\title{
INTEGRATED MANAGEMENT OF AGRICULTURE DRAINAGE WATER REUSE TO NOURISH NUBARIA CANAL
}

\author{
Hossam M. Moghazy ${ }^{1}$, Mohamed M. Sobeih ${ }^{2}$, Gamal A. Kamel ${ }^{3}$ \\ Esam E. Helal ${ }^{2}$ and Mahmoud A. El-Hadad ${ }^{4}$ \\ 1- Irrigation Engineering and Hydraulics Dept., Faculty of Eng., Alexandria University, Egypt \\ 2- Irrigation Engineering and Hydraulics Dept., Faculty of Eng., Minufiya University, Egypt \\ 3- Drainage Research Institute, National Water Research Center, Kanater, Egypt \\ 4- West Delta Drainage Region, Egyptian Public Authority for Drainage Projects
}

\begin{abstract}
In this study, the quality of the Nubaria canal water was investigated before and after mixing drainage water with Nubaria canal. Flow and water quality profiles have been estimated along the canal through the mathematical model, QUAL2K. The model has been calibrated according to the field data collected during summer and winter of the year 2007. The study included electrical conductively (EC), Biological Oxygen Demand (BOD) and ammonia $\left(\mathrm{NH}_{3}\right)$.

From the results obtained, the QUAL2K model appears to be useful for estimating water quality of Nubaria canal. Dynamic management is the most appropriate solution for controlling water quantity and quality of drainage water expected to be reused through mixing with Nubaria canal. Moreover, the salt and waste assimilative capacity of a canal could be calculated. Reusing of mix project drainage water, by discharge of 0.50 million $\mathrm{m}^{3} / \mathrm{d}$ does not affect the Nubaria water canal. There are clear effects in the Nubaria canal water today due to drainage water specially drain 3.

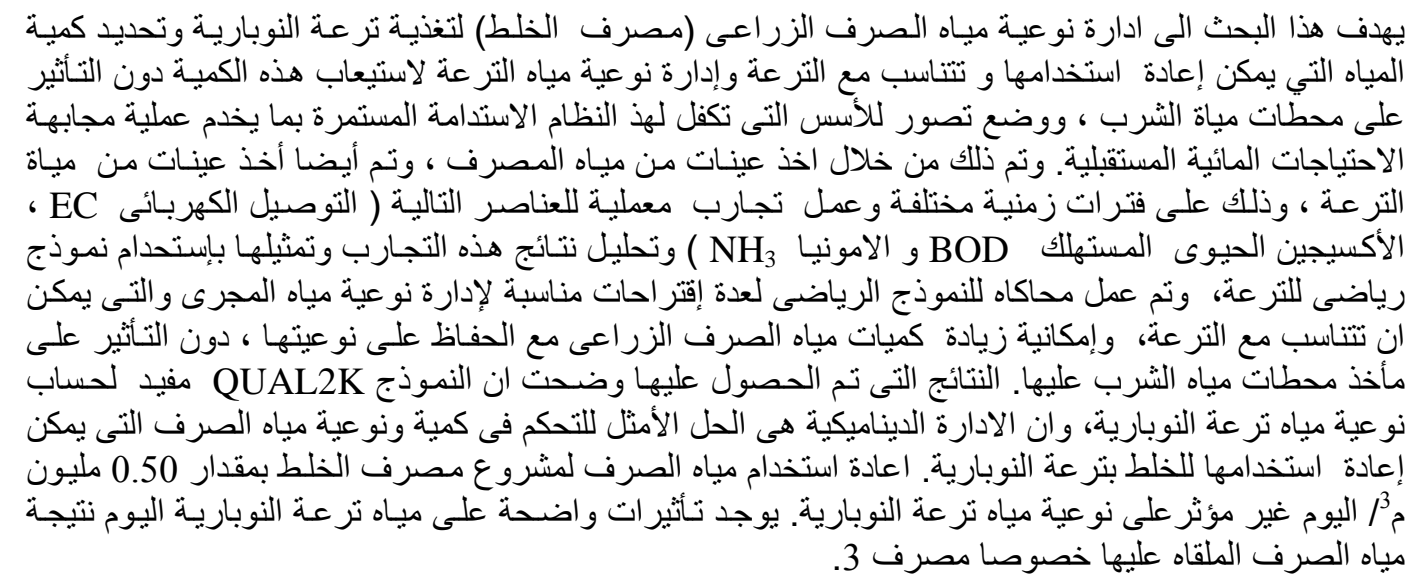

Keywords: Water quality models, drainage water reuse, Nubaria canal, mixing drain project, integrated management

\section{INTRODUCTION}

Agriculture is the largest consumer of available water resources in Egypt. On the other hand, drainage from irrigated lands is one of the major causes of water logging and water pollution. Water availability for irrigation could be enhanced through judicious and proper use of saline drainage water. The development of crops with increased salt tolerance and the adoption of new crop pattern and water management strategies enable the use of more saline drainage water for crop production.
The reuse of drainage water for irrigation started in the early of 1928 Abdel-Rashid, [2] through the Ministry of Water resources and Irrigation (MWRI) program. In 1928, Upper Serw pump station in the Eastern Delta was constructed to lift the Serw drain water and mix it with Damietta Branch water. In 1930, an additional Serw Pump station was constructed to support the main Serw Pump station. Two levels of drainage reuse are practiced in Egypt; they are official and unofficial Drainage use.

In the past decade, several mathematical models have been presented for evaluating and predicting water 
quality in streams. The most commonly models used are: multimedia fate models (Mackay and EUSES models), hydrodynamic models (Mike11 and QUASAR models), steady state models (QUAL2E and QUAL2K models) and finally stochastic models (TOMCAT and GREAT-ER models) $[4,8]$.

The water quality in drainage system in Egypt seems to be quite complicated. The reason is that the drainage network collects different types of water. Abdel- Gawad, [1].

Nagy and Salem, [11] investigated the quality of the omoum drain water. Flow and water quality profiles have been estimated along the drain through the water quality model, QUAL2E. The model is used for calibrating the de-oxygenating rate in the drain by utilizing measured field data report by issue Drainage Research Institute (DRI). Primary waste water treatment plants are proposed at specific locations along the drain. The study presented a design chart identifying the optimal amount of fresh water needed for the dilution of drainage water.

In this paper, a proposal for improving surface water quality is presented. The QUAL2K model was selected as the best available model for Nubaria canal. It has been the most widely used stream model that is numerically accurate and includes an updated kinetic structure for most conventional (Yang, [15]). The QUAL2K is applied to estimate the impact of discharged of drainage water on quality of Nubaria canal. The study presents a plan to control the Water quality of drainage system in Nubaria canal, in order to feed it by additional drainage water.

\section{DESCRIPTION OF MIXING DRAIN PROJECT}

Mixing drain project is located near Hosh Easa city, El-Behaira governorate. Its length is $13.5 \mathrm{~km}$ and serves an area of about 285,000 feddans. The bed width of the drain is $24.00 \mathrm{~m}$ and the side slope is $3: 2$. Its designed flow rate is $48 \mathrm{~m}^{3} / \mathrm{sec}$.

The main objective of this project is to save $1 \times 10^{9} \mathrm{~m}^{3} /$ year from Truga pump station P.St., Shereshra P.St., and Abo Hommes drainage catchments areas to feed Nubaria canal at km46.00 as shown in Figure (1). This will be established by building control regulator on Umoum drain directly downstream of Truga P.St.at km25.00 to reverse water direction to Shereshra drain and mixing drain instead of throwing it into the sea.

Three pump stations have been constructed. These are pump station No.1 (P.St.1) at km 13.5, P.St.2 at $\mathrm{km} 5.200$ and P.St.3 at km 0.700 on the Mixing drain for increasing water level to reach Nubaria canal water level. Table (1) shows the hydraulic characteristics of the pump stations of the Mixing Project.

\section{NUBARIA CANAL}

Nubaria canal is the largest main canal in western Nile Delta. The total served area by Nubaria canal is 1085053 feddans. The water supplies mounts to 21.6 million cubic meters per day $(\mathrm{MCM} / \mathrm{d})$. The actual water demand for the area is $30.8(\mathrm{MCM} / \mathrm{d})$. In order to face the gap between the water demand and the water supply, an additional discharges of 9.2 $(\mathrm{MCM} / \mathrm{d})$, is required as shown in Tables (2) (ELmedany, [6]). .Table (3) shows hydraulic characteristics of Nubaria canal (Hydraulic Research Institute, [7]).

\subsection{Field Measurements and Results}

The study area covers the regulator at $\mathrm{km} 28.000$ to the drinking intake at $\mathrm{km} 66.00$ as shown in figure (2). A monitoring program in Nubaria canal was set to monitor the drainage water quantity and quality for the proposed drainage reuse location. The objective of this program is to investigate the availability and suitability of the drainage water to feed Nubaria canal. Some important parameters were estimated and were compared to law $48 / 1982$ [9]. The results were introduced to a water quality mathematical model "QUAL2K" to suggest and predict different strategies for safe reuse of the drainage water to feed Nubaria canal and to choose the appropriate amount of water for mixing.

Field Measurements were carried out during January to December 2007 at Nubaria canal. 9 samples were collected monthly and examined in the laboratory .The samples were analyzed in the laboratory of the Drinking Water Company in Alexandria. 5 samples from Nubaria canal and 4 samples from the 4 drains that discharge into Nubaria canal as shown in Figure (2). 4 parameters were tested for each sample, (the electrical conductivity EC, $\mathrm{NH}_{3}, \mathrm{BOD}$ and Total Dissolved Solids TDS). All the parameters were determined in accordance with the American standard methods for the examination of water and waste water (Lenor et. al, [10]).

From the analysis, it was found that water quality along the Nubaria canal ranges from 197 to $360 \mathrm{mg} / \mathrm{l}$ for TDS, 8 to $20 \mathrm{mg} / \mathrm{l}$ for BOD and 0.01 to $0.46 \mathrm{mg} / \mathrm{l}$ for $\mathrm{NH}_{3}$, as Shown in fig.3. From the figure, it could be noticed that the TDS, NH3 and BOD concentrations varied from one site to another and from one season to another along the canal due to the changes in drainage water quality and quantity that are reused into the canal. Water quality along the mixing Drain ranges from 800 to $1600 \mathrm{mg} / \mathrm{l}$ for TDS, 2 to $18 \mathrm{mg} / \mathrm{l}$ for BOD and 0.5 to $3.5 \mathrm{mg} / \mathrm{l}$ for $\mathrm{NH}_{3}$ .Also, fig. 4 shows the variations of the TDS, $\mathrm{NH}_{3}$ 
and BOD concentrations from one month to another along the mixing drain.

\section{NUBARIA CANAL SIMULATIONS}

Canal modeling, was based on a steady flow conditions in the canal. From the regulator at $\mathrm{km}$ 28.00 to the drinking intake at $\mathrm{km} 66.00$, The QUAL2K model was used to simulate the existing hydraulic conditions and concentration of the biological Oxygen Demand (BOD), Electric Conductivity (EC) and Ammonia $\left(\mathrm{NH}_{3}\right)$ at Nubaria canal. The data provided by the monitoring program (DRI, [5]) and by field measurements, gave the most substantial constituents, which are considered as input variables to simulate the canal water quality, as listed in table 4.

\subsection{Model Theory}

The water quality model QUAL2K was used to study the quality of Nubaria canal water. In this model the stream is conceptualized as a one-dimensional string of completely mixed segments that are linked sequentially via the mechanisms as adjective transport and dispersion. The model uses a finitedifference solution for the adjective dispersion mass transport equation and also has the capability performing an uncertainty analysis. The model permits the solution of 36 water quality constituents. The stream could be divided into 100 reaches and each reach has 1000 computational elements. Each computational element has constant of hydrological characteristics and reaction constants.

The modeling tool QUAL2Kw has a general mass balance for a constituent concentration ci (Fig. 5) in the water Column of a reach $i$ (the transport and Loading terms are omitted from the mass balance equation for Bottom algae modeling) as (Pelletier et al.,[13])

$$
\frac{d c_{i}}{d t}=\frac{Q_{i-1}}{V_{i}} c_{i-1}-\frac{Q_{j}}{V_{i}} c_{i}-\frac{Q_{a b, i}}{V_{i}} c_{i}+\frac{E_{i-1}}{V_{i}}\left(c_{i-1}-c_{i}\right)+\frac{E_{i}}{V_{i}}\left(c_{i+1}-c_{i}\right)+\frac{W_{i}}{V_{i}}+S_{i}
$$

Where:-

Qi = flow at reach i $[1 / \mathrm{d}]$

Qab,i $=$ abstraction flow at Reach i [1/d]

$\mathrm{Vi}=$ volume of reach I [1]

$\mathrm{Wi}=$ the external load- ing of the constituent to reach i $[\mathrm{mg} / \mathrm{d}]$

$\mathrm{Si}=$ sources and sinks of the constituent due to reactions and mass trans-fer mechanisms $\quad[\mathrm{mg} / \mathrm{l} / \mathrm{d}]$

$\mathrm{Ei}=$ bulk dispersion coefficient between reaches $[1 / \mathrm{d}]$

Ei-1, Ei are bulk dispersion coef- ficients between reaches $i-1$ and $i$ and $i$ and $\mathrm{i}+1 \quad[\mathrm{l} / \mathrm{d}]$

$\mathrm{Ci}=$ concentration of water quality constituent in reach i $\quad[\mathrm{mg} / \mathrm{L}]$

$\mathrm{t}=$ time [day]

Figure 6 represents the schematic diagram of interacting water quality state variables. The complete description of process of interacting water quality state variables is available in (Pelletier and Chapra [14]).

Where:-

ab: bottom ap: hytoplankton mo: detritus algae

cs: slow cf: fast CBOD cT: total CBOD inorganic carbon

o: oxygen no: organic na: ammonia nn: nitrate po: organic pi: inorganic nitrogen phosphorus phosphorus

\subsection{Input Data}

The study area was simulated by dividing it into five reaches. Each reach has a constant hydraulic data, initial condition, and incremental flow for all computational elements within the reach. The model assumes a complete mixing effluent in the stream. In the simulation, the five feeding source points (one fresh water and four drainage water) as shown figure 2. The geometrical properties of the canal reaches were obtained from the longitudinal section of the canal, by Nubaria irrigation directorate [12]. The discharge, cross section area, and water depth are measured by Hydraulic Research Institute (HRI, [7]), table 3 .

\subsection{Model Calibration}

The used model was calibrated. The calibration data for ambient water quality were based on Nubaria canal field sampling effort in 2007, Table 5. Channel dimensions and cross Section is based on field physical measurement taken by HRI, 2003, Table 3. Rating curve coefficients and exponents were developed using the equations in (Chapra and Pelletier, [3]).

For water quality calibration, the modeled concentrations for the following parameters were compared with observed data in order to provide guidance on parameter adjustment: Discharge Q, EC, $\mathrm{BOD}$, and $\mathrm{NH}_{3}$. The model is considered reasonably calibrated because the model simulated pollutant of interest within the range shown by the observed data. Fig.7. shows that a good calibration of the model to the 2007 data was achieved. 


\subsection{Tested Scenarios}

The water quality of Nubaria canal was simulated by QUAL2K model (Case 1) in the maximum water requirements season. Figure (2) shows the scheme of Nubaria canal before mixing, the discharge of Nubaria canal water at $\mathrm{km} 28.00$ at this season is $123.670 \mathrm{~m}^{3} / \mathrm{s}$, this was named "Base Case" in the representation of results.

An integrated management strategy was set for the canal to use drainage water without affecting the drinking water intakes. The quality of Nubaria canal water was simulated by QUAL2K model (Case 2) at maximum water requirements and different scenarios were introduced to manage the drains that flow into the Nubaria canal, Figure (8)

First Scenario "without drain 3" It is proposed to mix the water of drain No.3 to Boston Canal and study the quality of Nubaria canal water, during maximum water requirements. The discharged drainage water from this drain at this season is 14 $\mathrm{m}^{3} / \mathrm{s}$.

Second Scenario "without drain 1and 3 " It is proposed to mix the water of drain 1 to El-Nasr Canal and study the quality of Nubaria canal water, during maximum water requirements. The discharged drainage water from this drain at this season is 10 $\mathrm{m}^{3} / \mathrm{s}$.

Third Scenario "adding $\mathbf{Q}^{\prime \prime}$ It is proposed to increase the discharge of Nubaria canal up to 1.5million cubic meter/day from El-Rayah ELBehairy and without drain No. 3 and No.1, although Bostan drain still discharges its water to Nubaria canal, and study the quality of Nubaria canal water, during maximum water requirements. The discharge of Nubaria canal water at $\mathrm{km} 28.00$ at this season is $141 \mathrm{~m}^{3} / \mathrm{s}$.

Also, an integrated management strategy for the Mixing drain was set to identify the suitable amount of water that could be reused. In this case QUAL2K model (Case 3) was used to simulate the maximum water requirements and introduce different scenarios to manage and operate the pump stations on the drains, Figure (9).

First Scenario " adding Q1" It is proposed to operate pumps 2 and 3 with discharge Q1 and study the quality of Nubaria canal water, during the summer where the crops need high water requirement. The discharge of drainage water (Q1) after Operating P.S. (2) and P.S (3) at this season is $5.8 \mathrm{~m}^{3} / \mathrm{s}$.

Second Scenario "adding Q2" ' It is proposed to operate the pump station1 with half of its capacity with discharge Q2 and study the quality of Nubaria canal water, during the summer where the crops need high water requirement. The discharge drainage water (Q2) after Operated P.S. (1), P.S. (2) and P.S (3) is $17.4 \mathrm{~m}^{3} / \mathrm{s}$.

Third Scenario "adding Q3" It is proposed to operate the pump station 1 with its full capacity with discharge Q3 and study the quality of Nubaria canal water and stop the shereshra pump station, during the summer. The discharge of drainage water (Q3) after Operating P.S. (1), P.S. (2) and P.S (3) is $23.15 \mathrm{~m}^{3} / \mathrm{s}$..

The best solution was chosen and compared to the present situation or standards of mixing the agricultural drainage water with the canal and the appropriate amount of water for reuse was specified (Case 4).

\section{RESULTS}

The results of the simulated scenarios were obtained, analyzed and represented on Figures 10 to 12 . It is clear that there is a variation in the concentration of the modeled parameters (BOD, NH4 and EC) along Nubaria canal at maximum water requirements.

Figs.10 shows the EC values in Nubaria canal due to adding drainage water. Variations can be observed in water quality parameter along Nubaria canal when operating the Pump Stations with Q1, Q2 and Q3 discharges [Case3]. The EC values along Nubaria canal increased after adding discharge Q1 by9\%, Q2 by $27 \%$ and Q3 by $45 \%$.

There are variations in water quality parameter along Nubaria canal after adding discharge Q1 or Q2 or Q3 when applying (S1), (S2) and (S3) [Case3 and Case2].

- $\quad$ The EC values along Nubaria canal decreased when applying (S1) by $23 \%,(\mathrm{~S} 2)$ by $38 \%$ and (S3) by $42 \%$ after adding $\mathbf{Q 1}=\mathbf{5 . 8} \mathbf{~ m}^{\mathbf{3}} / \mathbf{s}$.

- The EC values along Nubaria canal decreased when applying (S1) by $16 \%,(\mathrm{~S} 2)$ by $27 \%$ and (S3) by $31 \%$ after adding $\mathbf{Q} 2=\mathbf{1 7 . 4} \mathbf{~ m}^{\mathbf{3}} / \mathrm{s}$

- The EC values along Nubaria canal decreased when applying (S1) by $13 \%$, (S2) by $21 \%$ and (S3) by $26 \%$ after adding $\mathbf{Q 3}=\mathbf{2 3 . 1} \mathbf{~ m}^{\mathbf{3}} / \mathbf{s}$

- These values are complying with the standard limits of the national law 48/1982.

Figs.11 shows the values of BOD in Nubaria canal due to adding drainage water. The BOD values along Nubaria canal increased after adding discharge Q1 by $1 \%$, Q2 by $9 \%$ and Q3 by $19 \%$.

- These values are complying with the standard limit of the national law 48/1982.

- The BOD values along Nubaria canal decreased when applying (S1) by13\%, (S2) by $15 \%$ and (S3) by $16 \%$ after adding $\mathbf{Q 1}=\mathbf{5 . 8} \mathbf{~ m}^{\mathbf{3}} / \mathbf{s}$. 
- The BOD values along Nubaria canal decreased when applying (S1) by $8 \%$, (S2) by $22 \%$ and (S3) by $22 \%$ after adding $\mathbf{Q 2}=\mathbf{1 7 . 4}$ $\mathbf{m}^{3} / \mathbf{s}$

- The BOD values along Nubaria canal decreased when applying (S1) by 7\%, (S2) by $8 \%$ and $(\mathrm{S} 3)$ by $8 \%$ after adding $\mathbf{Q 3}=\mathbf{2 3 . 1} \mathbf{~ m}^{3} / \mathbf{s}$

- These values are still not complying with the standard limit of the national law 48/1982.

Figs. 12 shows the values of NH3 in Nubaria canal due to adding drainage water. The NH3 values along Nubaria canal increased after adding discharge Q1 by $15 \%$, Q2 by $38 \%$ and Q3 by $46 \%$.

- $\quad$ The NH3 values along Nubaria canal decreased when applying (S1) by67\%, (S2) by $73 \%$ and (S3) by $80 \%$ after adding $\mathbf{Q 1 = 5 . 8} \mathbf{~ m}^{3} / \mathbf{s}$.

- $\quad$ The NH3 values along Nubaria canal decreased when applying (S1) by $56 \%,(\mathrm{~S} 2)$ by $67 \%$ and (S3) by $72 \%$ after adding $\mathbf{Q} 2=\mathbf{1 7 . 4} \mathbf{~ m}^{3} / \mathbf{s}$

- $\quad$ The NH3 values along Nubaria canal decreased when applying (S1) by53\%, (S2) by $63 \%$ and (S3) by $68 \%$ after adding Q3=23.1 $\mathbf{~ m 3 / s . ~}$

\section{CONCLUSIONS}

Based on this study; the following are the extracted conclusions:

1. There are great variations in $\mathrm{EC}, \mathrm{NH}_{3}$ and $\mathrm{BOD}$ concentrations from one site to another and from one season to another along the canal due to the changes in drainage water quality and quantity that are reused into the canal.

2. The QUAL2K model appears to be useful for simulating water quality in Nubaria canal under different conditions of reusing drainage water.

3. Drainage water from mix drain project and its branches has a good quality for irrigation under certain farm management and control.

4. Reusing the mix project drainage water, by discharge of $5.8 \mathrm{~m}^{3} / \mathrm{s}$ does not affect the Nubaria water canal.

5. Reusing the mix project drainage water without applying drain3, could be allowed if a discharge of $17.4 \mathrm{~m}^{3} / \mathrm{s}$ was added to the Nubaria canal water.

6. Reusing of mix project drainage water without applying drain 3 and drain 1 , could be allowed if a discharge of $23.15 \mathrm{~m}^{3} / \mathrm{s}$ was added to Nubaria water canal.

7. The BOD values along Nubaria canal, is higher than the law48/1982 in all scenarios, even with diverting drains No.1 and No. 3 from the
Nubaria canal. This is due to organic loads in the original water sources of the canal

8. The $\mathrm{NH}_{3}$ values along Nubaria canal are complying with the standard limit of the national law 48/1982.

9. Dynamic management is the most appropriate solution for controlling water quantity and quality of drainage water expected to be reused through mixing with Nubaria canal as water quality along drains is variable from one place to another and from time to time.

\section{REFERENCES}

[1] Abdel-Gawad, S.T.," Reuse of agriculture drainage water", Academy of Science research and Technology - Board of Food, Agriculture and Irrigation Researches, Cairo, June, 1998.

[2] Abdel-Rashid, A.,"Impact of power stations waste discharge on aquaculture in the Nile River", Final report, USAID project 2630152.2002.

[3] Chapra, S. C., and G. J. Pelletier, "QUAL2K: A Modeling Framework for Simulating River and Stream Water Quality: Documentation and Users Manual" Civil and Environmental Engineering Dept., Tufts University, Medford, MA, November 2003.

[4] Cox, B. A.,"A review of currently available instream water quality models and their applicability for simulating DO in lowland", I.J. for $S$. research into the Environment and its relationship with Humankind, 314-316,pp. 335377, Wallingford, UK, 2003.

[5] Drainage Research Institute, Project Team, (2003). "Drainage water status in the Nile Delta", Yearbook 2002/2003, Delta Barrage, ElQanatir, Egypt

[6] El-Medane, (2007). "Study of irrigation case and efficiency of water channels network, problem and solution ". Alexandria Egypt

[7] Hydraulic Research Institute (HRI, 2003). "Evaluate the Efficiency of the Channel Distribution System in the West Delta" ELkanater, Cairo, Egypt

[8] Keller, V., "Risk assessment of down -the -drain chemicals", I. J. for S. research into the Environment and its relationship with Humankind, Wallingford, UK, 2005.

[9] Law 48/1982 protection for the Nile river and water channels from pollution. 
[10] Lenore S., Amold E. and Andrew D. (1998)," Standard Methods for the Examination of water and waste water", 20th Edition, 1998.

[11]Nagy, H.M and Salem, A.A." Evaluation of Drainage Water Quality for Reuse, A Case Study of the Umoun Drain in Egypt". Lowland Technology in Transactional Vol 5, No2. December,2003.

[12] Nubaria Irrigation Directorate, "The geometrical properties of Nubaria canal" MWRI, Egypt 2007.

[13]Pelletier, G.J., Chapra, C.S., Tao, H., "QUAL2Kw, A framework for modeling water quality in streams and rivers using a genetic algorithm for calibration. Environ". Model, Software, 21,419-4125,2006.

[14] Pelletier, G.J., Chapra, S.C., (2005)."QUAL2Kw theory and documentation (version 5.1), A Modeling Framework for Simulating River and Stream Water Quality", retrieved 10 May 2005 from: http://www.ecy.wa.gov/programs/eap/ models./

[15] Yang, M. D., R. M. sykes, and C. J. Merry, "Estimation of algal biological parameters using water quality modeling and SPOT Satellite data", Ecological Modeling, 125, pp. 1-13,2000.

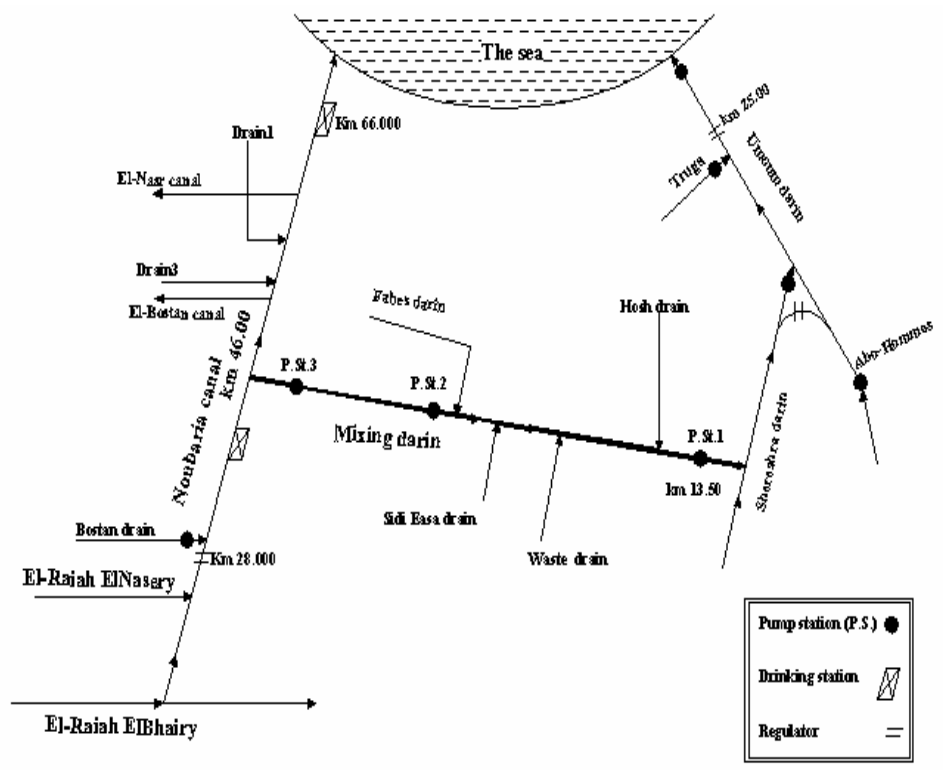

Fig. 1 Mixing drain project in Nubaria canal

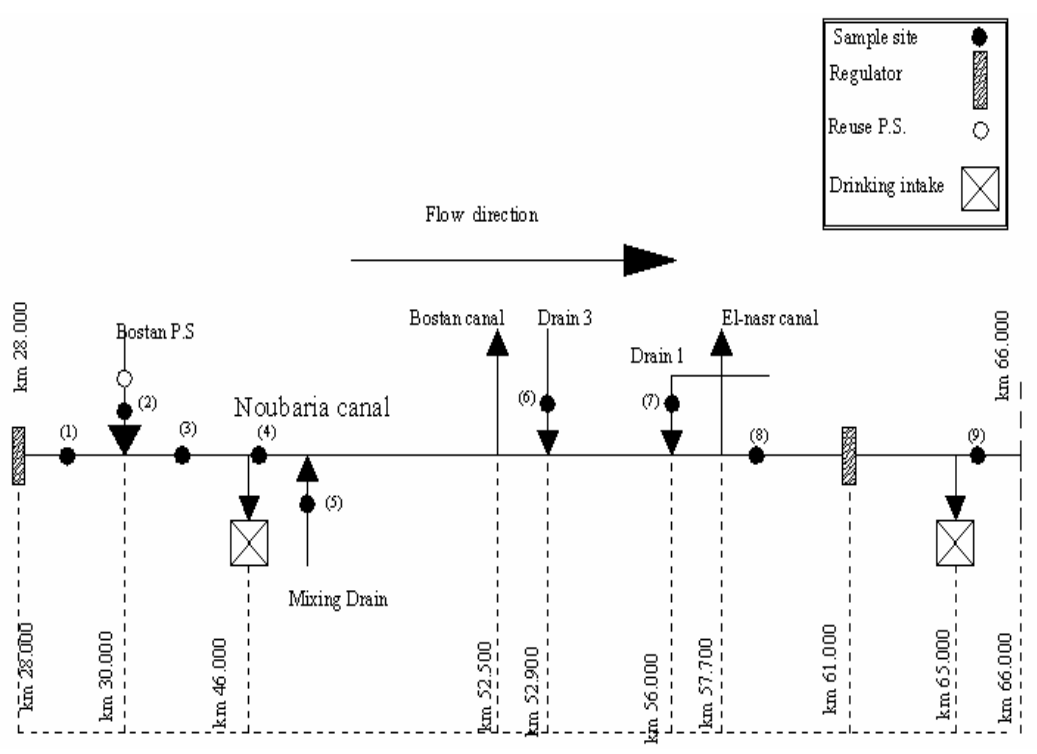

Fig. 2 Schematic plan of Nubaria canal system 
H. M. Moghazy, Mohamed M. Sobeih, G. A. Kamel, E. E. Helal,M. A. El-Hadad, "Integrated Management ..."
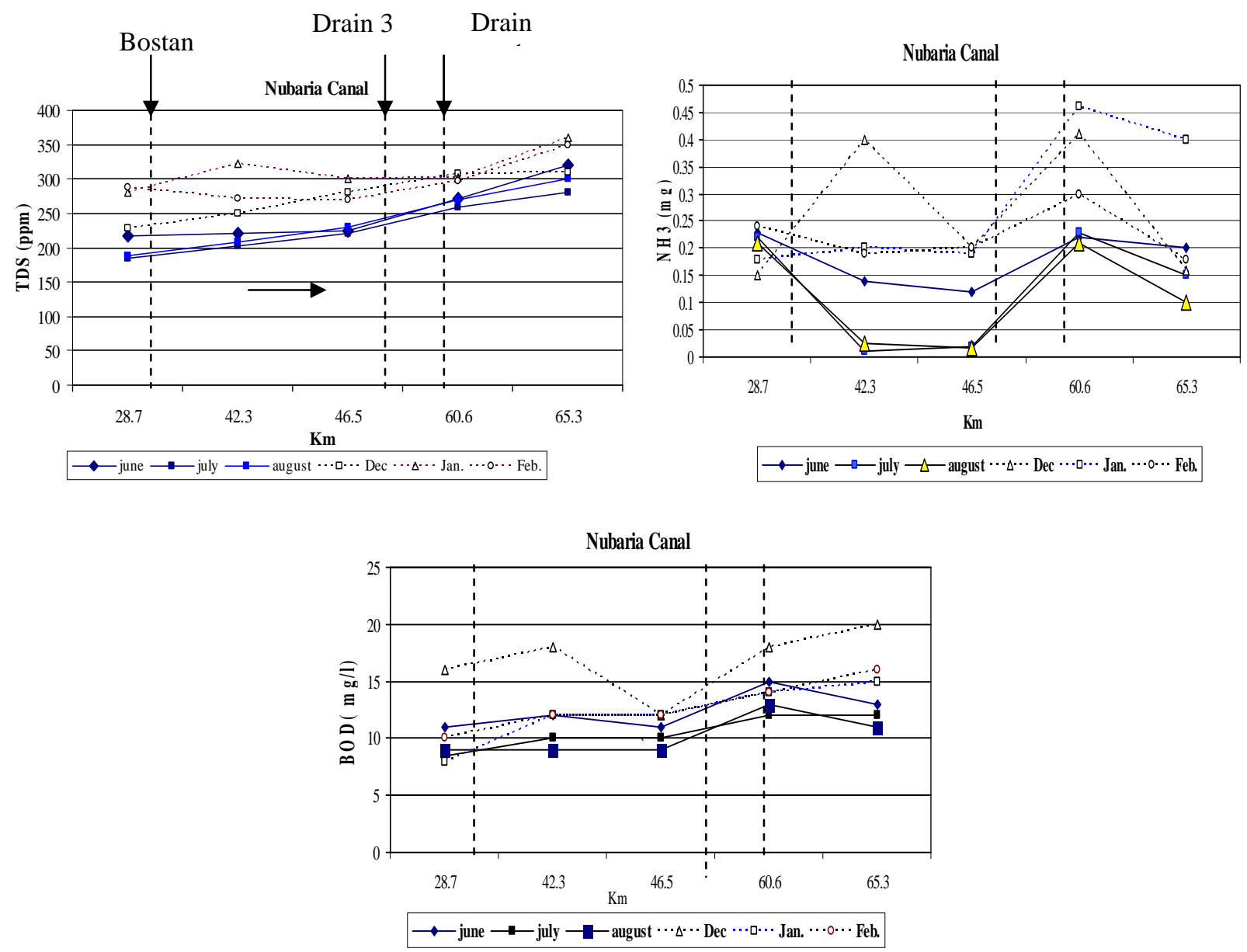

Fig.3. Monthly concentrations of TDS, NH3 and BOD along Nubaria Canal 
H. M. Moghazy, Mohamed M. Sobeih, G. A. Kamel, E. E. Helal,M. A. El-Hadad, "Integrated Management ..."
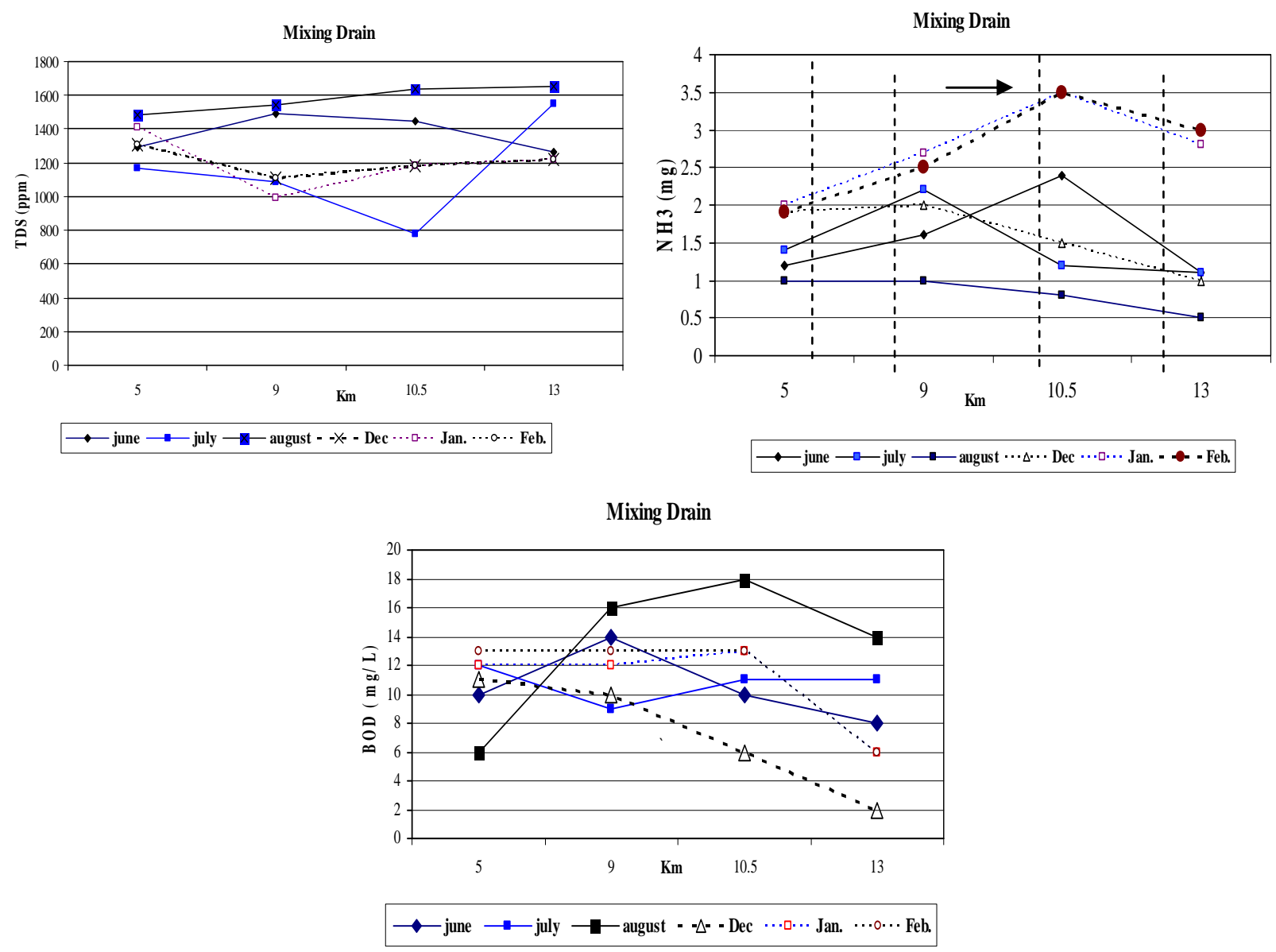

Fig. 4 Monthly concentrations of TDS, $\mathrm{NH}_{3}$ and BOD Along Mixing Drain
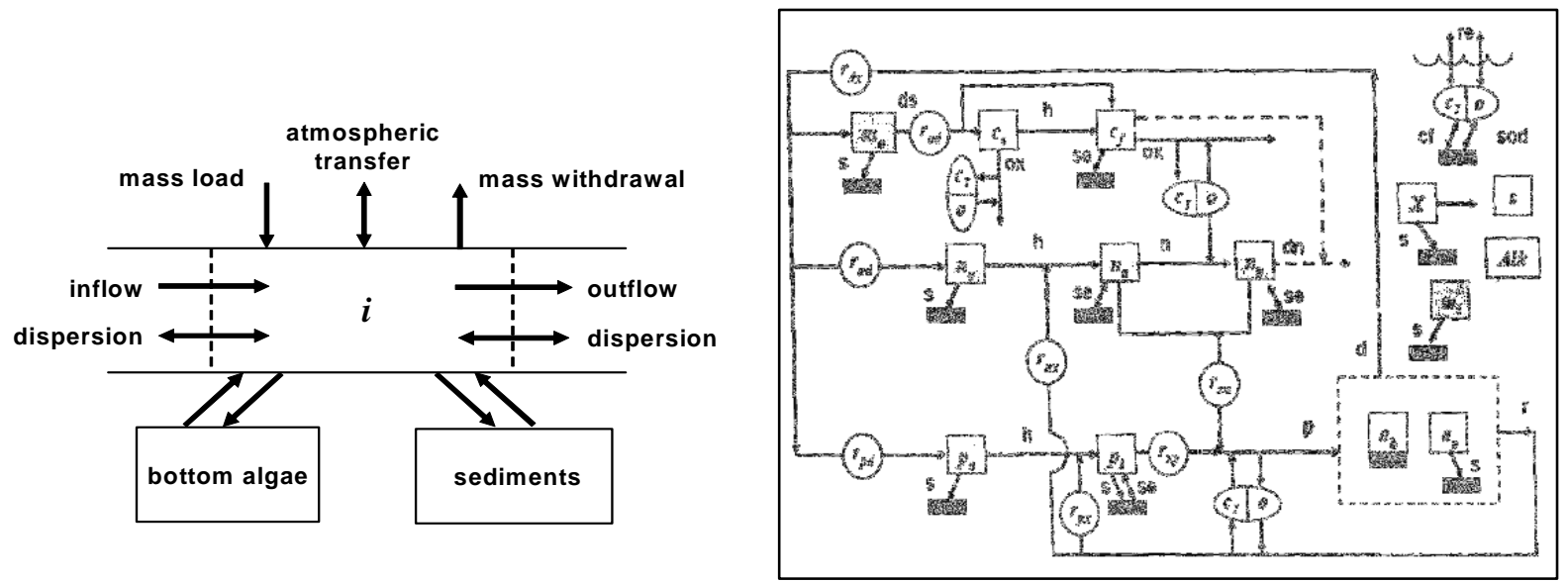

Fig. 5 Mass Balance in a reach segment i

Fig. 6 Schematic diagram of interacting water quality state variables 
H. M. Moghazy, Mohamed M. Sobeih, G. A. Kamel, E. E. Helal,M. A. El-Hadad, "Integrated Management ..."

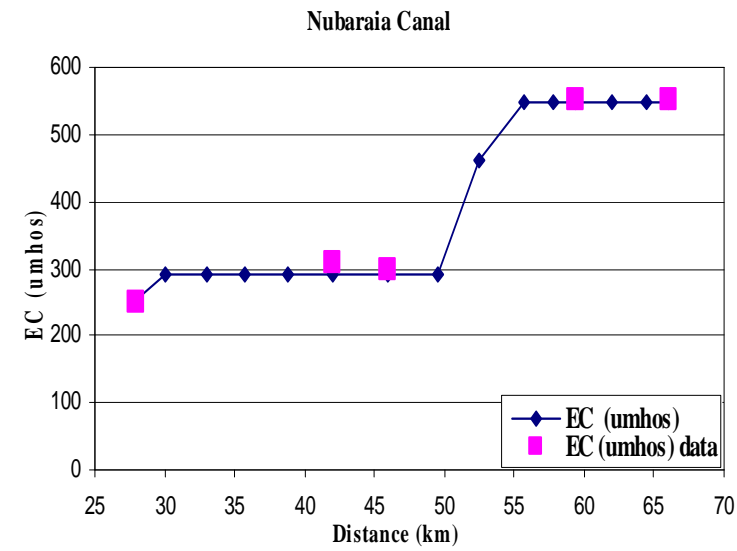

a - EC ( $\mu \mathrm{mhose} / \mathrm{cm})$ concentration

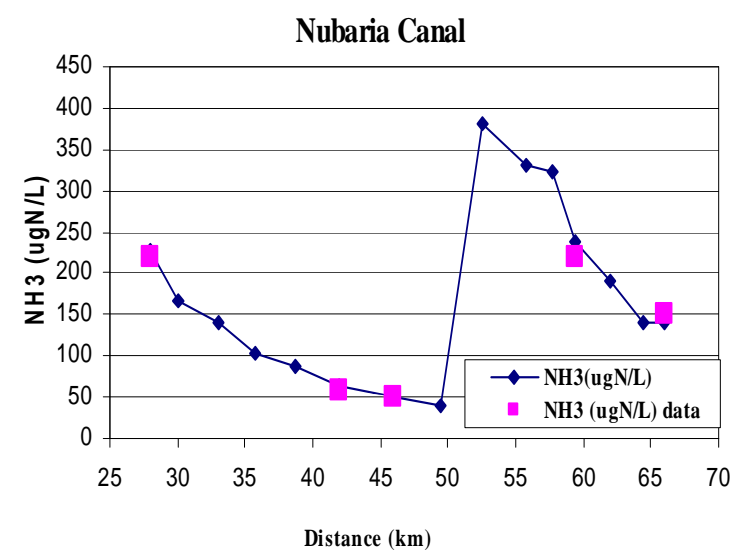

c- NH3 $(\mu \mathrm{g} / \mathrm{L})$ concentration

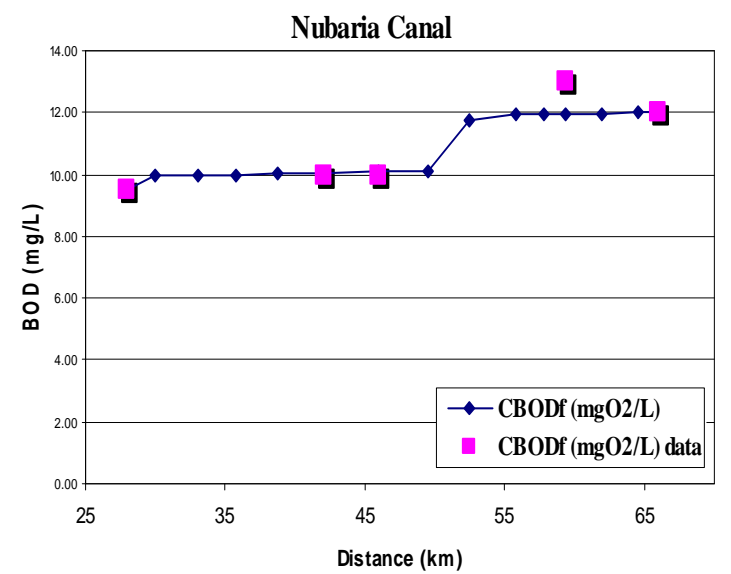

b- BOD (mg/L) concentration

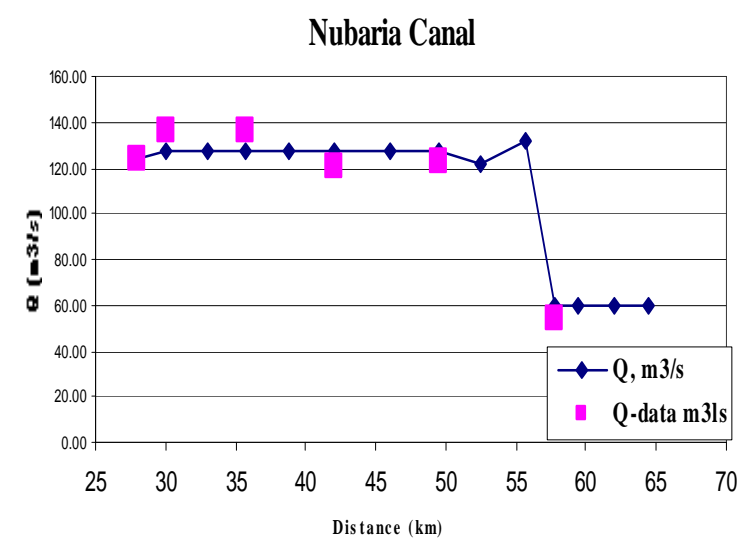

d- Discharge Q (m3/s)

Fig.7 Model Calibration Results

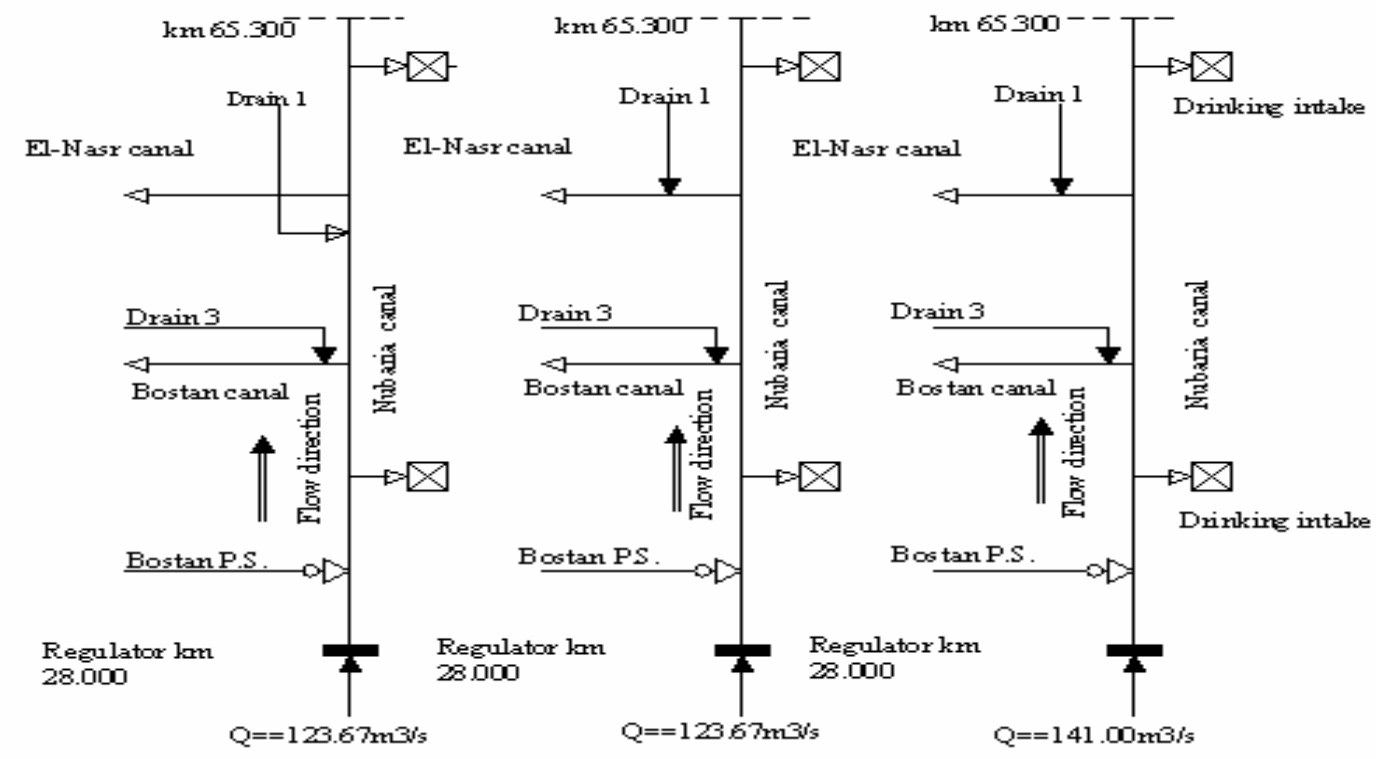

Fig.8 Different Scenarios to Manage the Drains that Flow into the Nubaria Canal 
H. M. Moghazy, Mohamed M. Sobeih, G. A. Kamel, E. E. Helal,M. A. El-Hadad, "Integrated Management ..."
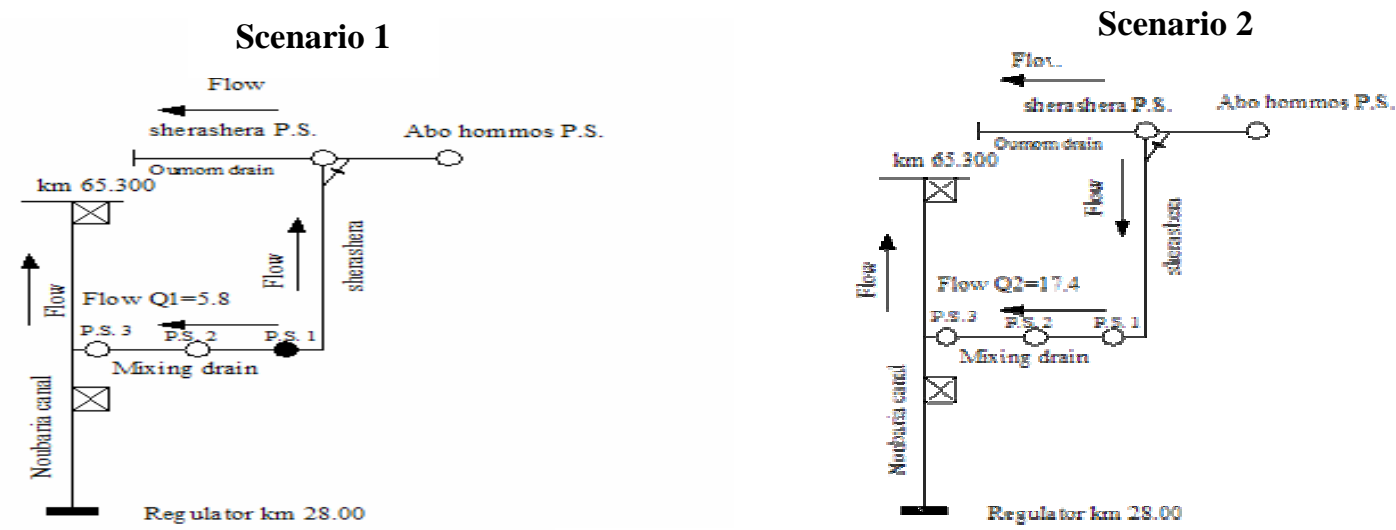

\section{Scenario 3}

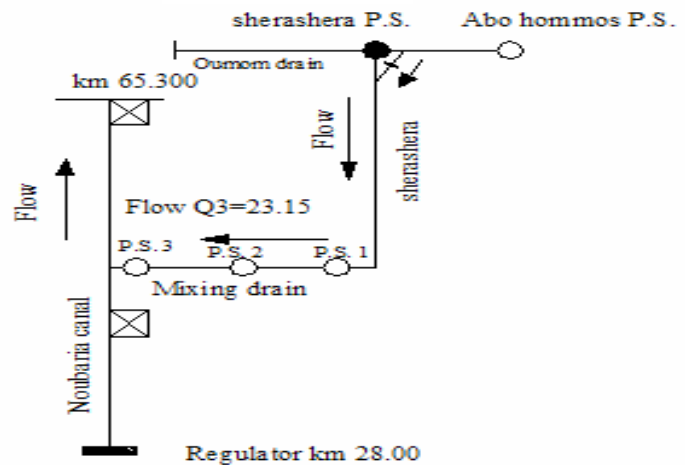

Fig. 9 Different Scenarios to Manage operate the pump station on the Mix Drain
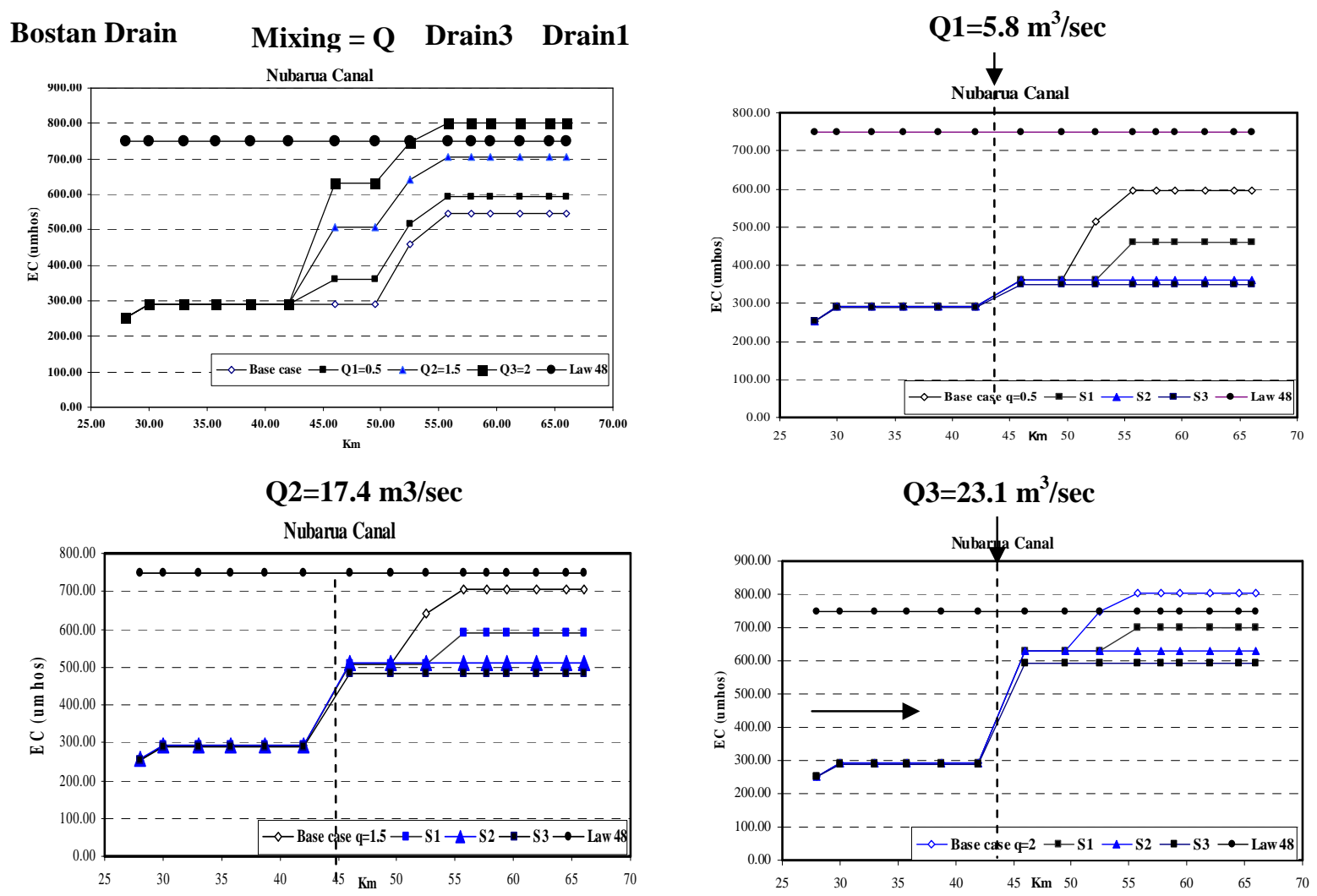

Fig. 10 EC for the different Scenarios in Nubaria Canal after applying (Case3) and (Case2) 
H. M. Moghazy, Mohamed M. Sobeih, G. A. Kamel, E. E. Helal,M. A. El-Hadad, "Integrated Management ..."
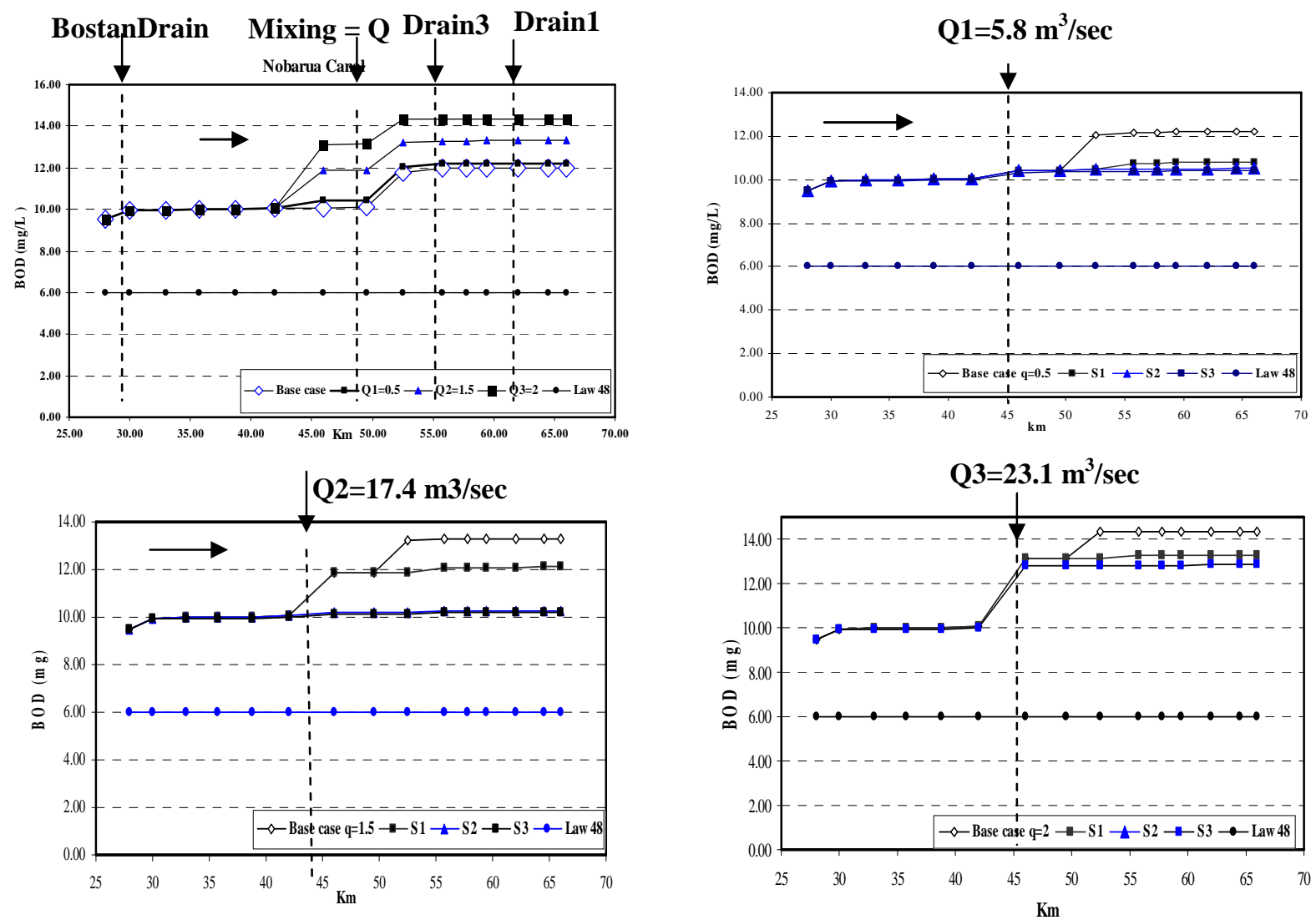

Fig. 11 BOD for the different Scenarios in Nubaria Canal (Case3) and (Case2)

Bostan Drain Mixing = Q Drain3 Drain1

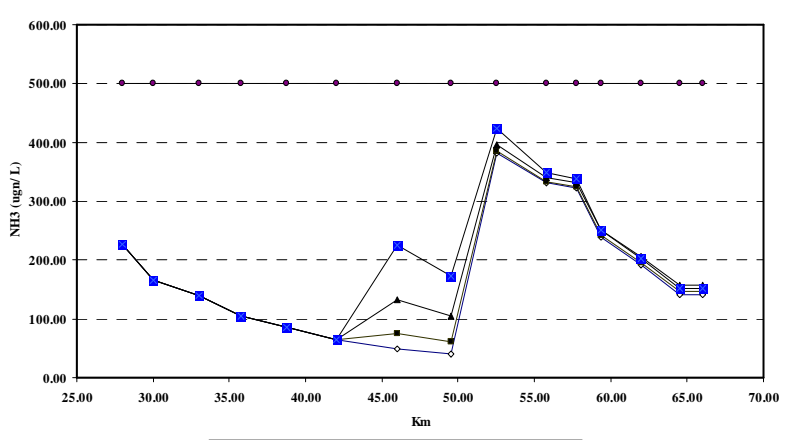

$-0-$ Base case $\rightarrow-01=0.5 \rightarrow-02=1.5 \rightarrow-03=2-\infty-$ Law 48

Q1=17.4 $\mathrm{m}^{3} / \mathrm{sec}$

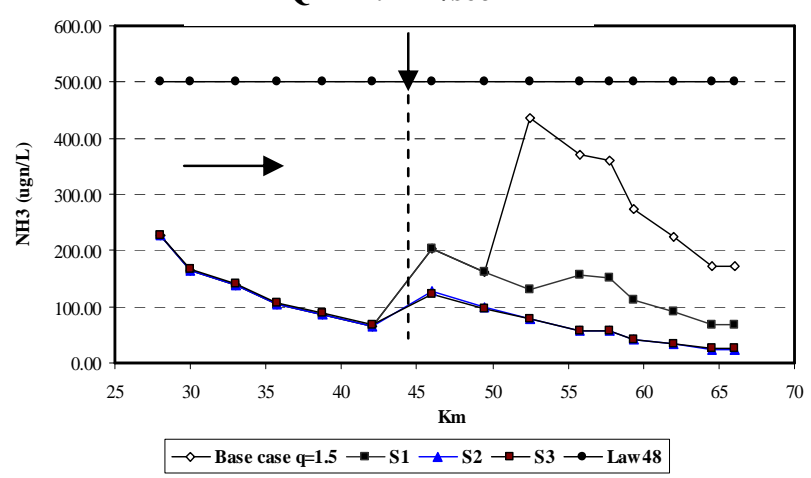

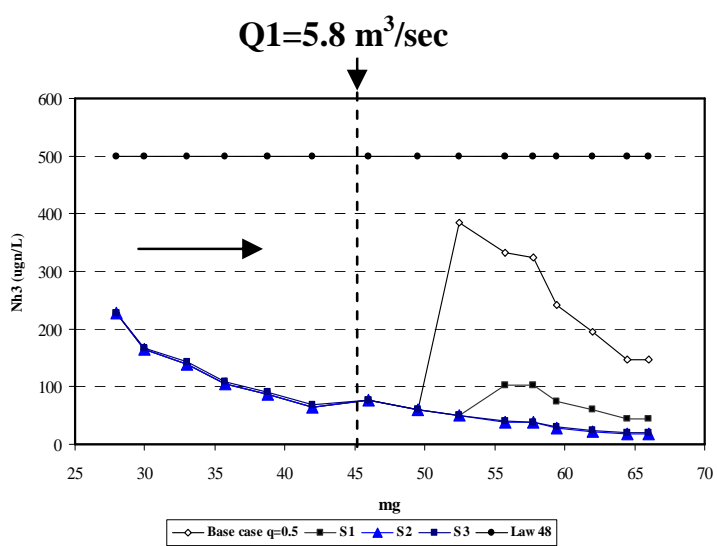

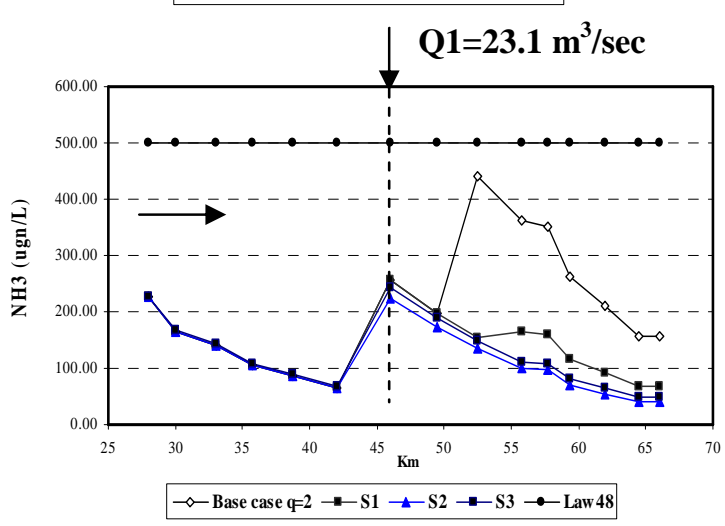

Fig. $12 \mathrm{NH}_{3}$ for the different Scenarios in Nubaria Canal (Case3) and (Case2) 
H. M. Moghazy, Mohamed M. Sobeih, G. A. Kamel, E. E. Helal,M. A. El-Hadad, "Integrated Management ..."

Table 1 The Designed Hydraulic Data for P.St. of the Mixing Project

\begin{tabular}{|c|c|c|c|}
\hline Item & P.S.1 & P.S.2 & P.S.3 \\
\hline Catchments area (fed.) & 232000 & 285000 & 5 \\
\hline No. of units & 5 & 5 & 12.5 \\
\hline
\end{tabular}

Table 2 Water balance for Nubaria Canal (EL-Medany, [6])

\begin{tabular}{|c|c|c|c|c|c|c|c|c|}
\hline \multirow{2}{*}{ Area } & \multicolumn{2}{|c|}{ Command (fedan) } & \multicolumn{2}{|c|}{$\begin{array}{c}\text { Water resources } \\
(\mathrm{MCM} / \mathrm{d})\end{array}$} & \multicolumn{4}{|c|}{ Water demand (MCM/d) } \\
\hline & $\begin{array}{l}\text { Surface } \\
\text { irrigation }\end{array}$ & $\begin{array}{l}\text { Modern } \\
\text { irrigation }\end{array}$ & $\begin{array}{l}\text { Nile } \\
\text { water }\end{array}$ & $\begin{array}{l}\text { drainage } \\
\text { water }\end{array}$ & Agriculture & industrial & navigation & Potable \\
\hline 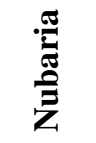 & 762244 & 322809 & 19.0 & 2.6 & 28.0 & 0.4 & 0.5 & 1.9 \\
\hline Total & \multicolumn{2}{|c|}{1085053} & \multicolumn{2}{|c|}{21.6} & \multicolumn{4}{|c|}{30.8} \\
\hline
\end{tabular}

Table 3 Hydraulically Data for Nubaria Canal (After HRI, [7])

\begin{tabular}{|c|c|c|c|c|c|c|}
\hline Reach & Km & Side slope & $\begin{array}{c}\text { Manning } \\
\text { Coefficient } \\
\text { "n" }\end{array}$ & $\begin{array}{c}\text { Bottom Width } \\
(\mathrm{m})\end{array}$ & $\begin{array}{c}\text { Longitudinal } \\
\text { Slope }\end{array}$ & $\begin{array}{c}\text { Flow } \\
(\mathrm{m} / \mathrm{s})\end{array}$ \\
\hline 1 & $28-38$ & $3: 1$ & 0.019 & 60.50 & 0.0001 & 136.0 \\
\hline 2 & $38-44$ & $3: 1$ & 0.019 & 38.00 & 0.0001 & 136.0 \\
\hline 3 & $44-48$ & $3: 1$ & 0.019 & 27.00 & 0.0001 & 121.8 \\
\hline 4 & $48-57$ & $3: 1$ & 0.019 & 34.00 & 0.0001 & 122.6 \\
\hline 5 & $57-66$ & $3: 1$ & 0.019 & 33.00 & 0.0001 & 53.7 \\
\hline
\end{tabular}


H. M. Moghazy, Mohamed M. Sobeih, G. A. Kamel, E. E. Helal,M. A. El-Hadad, "Integrated Management ..."

Table 4 Average water quality parameters for sampling locations

\begin{tabular}{|c|c|c|c|c|c|}
\hline Name & $\begin{array}{c}\text { Location } \\
(\mathrm{Km})\end{array}$ & $\begin{array}{c}\text { Flow } \\
\left(\mathrm{m}^{3} / \mathrm{s}\right)\end{array}$ & $\begin{array}{c}\text { EC } \\
(\mu \mathrm{mhose} / \mathrm{cm})\end{array}$ & $\begin{array}{c}\text { BOD } \\
(\mathrm{mg} / \mathrm{l})\end{array}$ & 18 \\
\hline Mixing Drain with Q1 & 46.300 & 5.8 & 1850 & 1500 \\
\hline Mixing Drain with Q2 & 46.300 & 17.4 & 2100 & 25 & 1800 \\
\hline Mixing Drain With Q3 & 46.300 & 23.15 & 2500 & 27 & 2000 \\
\hline Drain 3 & 52.900 & 14 & 2000 & 14 & 1140 \\
\hline Drain 1 & 56.00 & 10 & 1600 & 23 & 240 \\
\hline Bostan P.S. & 30.00 & 4 & 1500 & 2500 \\
\hline
\end{tabular}

Table 5 Average water quality in Nubaria Canal at maximum requirement

\begin{tabular}{|c|c|c|c|}
\hline $\begin{array}{c}\text { Location } \\
(\mathbf{K m})\end{array}$ & $\begin{array}{c}\mathbf{E C} \\
(\boldsymbol{\mu m h o s} / \mathbf{c m})\end{array}$ & $\begin{array}{c}\text { BOD } \\
(\mathbf{m g} / \mathbf{l})\end{array}$ & $\begin{array}{c}\mathbf{N H}_{\mathbf{3}} \\
(\boldsymbol{\mu \mathbf { g }} / \mathbf{L})\end{array}$ \\
\hline $\mathbf{2 8 . 7 0 0}$ & 250 & 9.5 & 220 \\
\hline $\mathbf{4 2 . 3 0 0}$ & 310 & 10 & 57 \\
\hline $\mathbf{4 6 . 3 0 0}$ & 300 & 10 & 50 \\
\hline $\mathbf{6 0 . 6 0 0}$ & 550 & 13 & 220 \\
\hline $\mathbf{6 5 . 3 0 0}$ & 550 & 12 & 150 \\
\hline
\end{tabular}

